\title{
Algumas Considerações Sobre A Educação Após Auschwitz De Adorno (1995)
}

\author{
Some Considerations About Education After Auschwitz Of Adorno
}

\author{
Ricardo Czepurnyj Ferrara
}

Mestre em Filosofia na Universidade São Judas (2013). Graduado bacharel em Filosofia pela Universidade São Judas Tadeu (2009) e bacharel em Sistemas de Informação pelo Centro Universitário Íbero - Americano - UNIBERO (2006). Docente do curso de Direito das Faculdades Integradas Campos Salles.ricardo.ferrara@gmail.com

\section{Resumo}

O terror de Auschwitz sintetiza-se no extermínio entre 3 a 4 milhões de judeus nos campos de concentração. Adorno (1995) investiga as possíveis relações de suas causas desse pérfido evento com a educação e a formação dos indivíduos. O acontecimento de Auschwitz demonstra que um episódio parecido pode ocorrer a qualquer momento, em qualquer lugar do mundo. De certa forma, o autor chega a conclusão de que a educação dos indivíduos, no passado, no presente e no futuro, traz sementes de barbárie, gênese de tal brutalidade. E não somente a formação dos indivíduos colabora com esse quadro, mas outras estruturas da sociedade fomentam a possibilidade de um novo Auschwitz.

Palavras chave: educação, cultura, violência, subjetividade, psicologia

\begin{abstract}
The Auschwit?, horror is synthesized in the death of 3 to 4 million jews in concentration camps. Adorno (1995) investigates the possible relationship of their causes of this perfidious event with the education and training of individuals. The event Auschwitz shows that a similar episode may occur at any time, anywhere in the world. In a way, the author comes to the conclusion that the education of individuals in the past, the present and the future, brings barbarity seeds, genesis of such brutality. And not only the formation of individuals collaborating with this picture, but other structures of society promote the possibility of a new Auschwit:
\end{abstract}

Keywords: education, culture, violence, subjectivity, psychology 


\section{Introdução}

O objetivo desta pesquisa é promover uma reflexão: Se Auschwitz foi regressão, então ainda está vigente os princípios norteadores que a fizeram tornar-se realidade. Estando esses princípios ainda vigentes, a possibilidade de um novo Auschwitz é enorme. Adorno (1995) reconhece que o pensador que mais trabalhou com eficácia, debruçado na cultura e na sociologia, foi Freud, que identificou que a civilização fomenta o seu avesso - as sementes anticivilizatórias:

Na abertura do "O mal-estar na civilização", que também pode ser traduzido como "O mal-estar na cultura", Frend afirma que: "É impossivel fugir à impressão de que as pessoas comumente empregam falsos padrões de avaliação - isto é, de que buscam poder, sucesso e riqueza para elas mesmas e os admira-nos outros, subestimando tudo aquilo que verdadeiramente tem valor na vida. No entanto, ao formular qualquer juizo geral desse tipo, corremos o risco de esquecer quão variados são o mundo bumano e sua vida mental. Existem certos homens que não contam com a admiração de seus contemporâneos, embora a grandeza deles repouse em atributos $e$ realizações completamente estranhos aos objetivos e aos ideais da multidão. Facilmente, poder-se-ia ficar inclinado a supor que, no final das contas, apenas uma minoria aprecia esses grandes homens, ao passo que a maioria pouco se importa com eles. Contudo, devido não só às discrepâncias existentes entre os pensamentos das pessoas e suas ações, como também à diversidade de seus impulsos plenos de desejo, as coisas
Em outros termos, o processo civilizatório carrega consigo a possibilidade de ser anticivilizatório. $O$ pano de fundo que marca esse cenário é o embate do plano racional e o plano irracional. É no sobressalto do elemento irracional que Adorno (1995) refere-se como desesperador.

Para Adorno (1995) quem ainda insiste em afirmar que este acontecido nem foi tão grave assim, de certa forma, já está defendendo o que ocorreu, e sem dúvida seria capaz de assistir ou colaborar se tudo acontecesse de novo. A Psicologia ensinou que o esclarecimento por si só não é suficiente para deter a dinâmica do inconsciente, contudo favorece a criação de um cenário propício para a resistência contra os extremismos:

"O termo esclarecimento provém do alemão Aufklãrung. Para Kant, "Esclarecimento [Aufklärung] é a saída do homem de sua menoridade, da qual ele próprio é culpado. A menoridade é a incapacidade de fazer uso de seu entendimento sem a direção de outro indivíduo. O homem é o próprio culpado dessa menoridade se a causa dela não se encontra na falta de entendimento, mas na falta de decisão e coragem de servir-se de si mesmo sem a direção de outrem. Sapere aude! Tem coragem de fazer uso de teu próprio entendimento, tal é o lema do esclarecimento. (...) se for feita então a pergunta: "vivemos agora uma época esclarecida [aufgeklärten]"? a resposta será: "não, vivemos em uma época de esclarecimento". Falta ainda muito para que os homens, nas condições atuais, tomados em conjunto, 
estejam já numa situação, ou possam ser colocados nela, na qual em matéria religiosa sejam capazes de fazer uso seguro e bom de seu próprio entendimento sem serem dirigidos por outrem. KANT, Immanuel. O que é esclarecimento"? Disponivel em: bttp:/ / coral.ufsm.br/gpforma/2senafe/ PDF/b47.pdf-Acesso em 29-05-2016 às 18:43

A justificativa se sustenta na relevância do tema para a história da filosofia medieval no ocidente. Um tópico não totalmente explorado e, portanto, não totalmente esclarecido na bibliografia a que esse tema pertence e sobre o qual muito pouco ou nada existe em português. O estudo dessa temática contribui significativamente para o aumento da bibliografia disponível em língua portuguesa.

A metodologia é a pesquisa bibliográfica e eletrônica para explorar adequadamente o tema trabalhado a partir da fonte primária do autor, e auxílio de outros autores.

O Referencial teórico tece algumas considerações sobre a educação após auschwitz de colocando em diálogo Adorno (1995) que rechaça o discurso idealista-utópico, da vertente que defende como o mundo deveria a ser. Enquanto Bauman, Zygmunt (1998) discute Modernidade e holocausto para que não se repita o episódio de Auschwitz.

\section{Análise Antropológica Da Sociedade}

Adorno (1995) apela para a conscientização do elemento desesperador irracional e para o método tentativa e erro, justificando que é preciso tentar, pois a sociedade não teve transformações significativas em vinte e cinco anos e Bauman diz que:

"O aumento da distância e - ou psíquica entre o ato e suas consequências produz mais do que a suspensão da inibição moral: anula o significado moral do ato e todo conflito entre o padrão pessoal de decência moral e a imoralidade das consequências sociais do ato. Com a maioria das ações socialmente significativas mediadas por uma extensa cadeia de dependências causais e funcionais complexas, os dilemas morais saem de vista e se tornam cada vez mais raras as oportunidades para um exame mais cuidadoso e uma opção moral consciente. (...) com o morticinio à distância, é provável que a relação entre a carnificina e atos absolutamente inocentes - como puxar o gatilho, ligar a corrente elétrica on apertar um botão num teclado de computador - permaneça puramente teórica (tendência enormemente favorecida pela mera diferença de escala entre o resultado e sua causa imediata incomensurabilidade que facilmente desafia a compreensão fundada na experiência do senso comum. É portanto, possivel ser o piloto que lança bombas em Hiroshima ou Dresde, destacar-se no cumprimento do dever em uma base de misseis teleguiados, projetar ogivas nucleares ainda mais devastadoras e tudo isso sem comprometer a própria integridade moral ou de forma alguma se diminuir moralmente (a invisibilidade das vitimas foi, compreensivelmente, um importante fator também nas infames experiências de Milgram. Com esse efeito de invisibilidade das vitimas 
em mente, é talvez mais fácil compreender as sucessivas melhorias da tecnologia no Holocausto" (BAUMAN, 1998, p. 45).

Seu método é o de analisar a sociedade como ela realmente é, sem sombras de representações e idealizações, em detrimento de uma retórica idealista. Como um exemplo dessas sementes anticivilizatórias, Adorno (1995) aponta que a guerra entre turcos e armênios configura-se o reaparecimento de nacionalismos exacerbados que resultaram em grandes genocídios. Por falar em genocídio, a criação da bomba atômica ilustra bem o cenário na qual Adorno (1995) se referia.

Em nome de nacionalismos inconseqüentes, populações inteiras foram dizimadas. A raiz desses acontecimentos, segundo Adorno (1995) tem duas perspectivas: a perspectiva objetiva, uma visão macro, na qual a trama social e política causam esses episódios sombrios e a perspectiva subjetiva, com o enfoque no indivíduo, filho dessa civilização que traz em si elementos de autodestruição. Para Adorno (1995) a situação não tem resolução eficaz quando há recorrência a valores transcendentais, nem menos a conscientização dos valores da minoria massacrada. Entre o assassino e o assassinado, é preciso diagnosticar o assassino e não o assassinado. Para Bauman:

\footnotetext{
"A maioria dos que executaram o genocídio eram pessoas normais, que passariam facilmente em qualquer peneira psiquiatrica conhecida, por mais
}

\begin{abstract}
densa e moralmente perturbadora. Isso também é intrigante, em especial quando visto em conjunto com a 'normalidade' daquelas estruturas da organização que coordenaram as açoes desses indivíduos normais no empreendimento do genocídio. Já sabemos que as instituições responsáveis pelo Holocausto, mesmo se consideradas criminosas, não eram, em nenhum sentido sociologicamente legítimo, patológicas ou anormais. As pessoas cujas ações elas institucionalizaram também não se desviavam dos padrões estabelecidos de normalidade” (BAUMAN, 1998, p. 39).
\end{abstract}

É necessário trazer à tona a engrenagem que torna o indivíduo capaz de realizar as mais altas atrocidades pelas mais míseras motivações. Sob esta ótica da subjetividade, o culpado não seria o assassinado, mas o assassino, que não realizaram uma reflexão séria e aguda sobre si mesmo. O conhecimento de si se fundamenta na autopreservação, tanto de si, quanto do outro:

\footnotetext{
"À medida que o quadro completo emerge da pesquisa histórica, surge também uma interpretação alternativa do Holocausto - possivelmente de mais crédito - como um evento que revelou a fraqueza e fragilidade da natureza bumana (a abominação do assassinato, a aversão da violência, o medo da consciência culpada e a responsabilidade pelo comportamento imoral) quando confrontada com a simples eficiência doa mais acalentados produtos da civilização; sua tecnologia, seus critérios racionais de escolha, sua tendência a subordinar pensamento e ação à praticidade da economia e da eficiência" (BAUMAN, 1998, p. 32).
}

Colocadas essas asserções, Adorno (1995) assevera que a educação tem sentido unicamente como educação dirigida a uma 
auto-reflexão crítica. Assim, a educação precisa deixar de ser mecânica e repetitiva, para ser qualitativa em todas as etapas da infância e da adolescência, principalmente na primeira infância, pois os elementos irracionais anticivilizatórios se alastraram de uma perspectiva jamais vista. A interconectividade social criou indivíduos claustrofóbicos prisioneiros dessa rede. Essa claustrofobia causa revolta que tende à violência e à irracionalidade.

Adorno (1995) fazendo uma análise antropológica da sociedade, constata que quanto mais uma sociedade se integra, mais traz em si características do seu avesso, ou seja, a desintegração. Essa contradição tem o poder de aniquilar a subjetividade, bem como qualquer mecanismo de proteção. Perdendo a sua identidade e suas qualidades, o indivíduo não tem o menor impedimento que o faça rechaçar a sedução do crime.

Ao tratar do tema Educação após Auschwitz, Adorno (1995) tem duas perspectivas para trabalhar com a questão: a primeira infância, fase decisiva para a formação humanística da criança, como foi dito anteriormente e o esclarecimento geral que fomenta uma cultura intelectual de reflexões aprofundadas, conscientização e formação da pessoa humana. Para o autor, essas duas perspectivas bem trabalhadas poderiam fazer com que a tragédia de Auschwitz não se atualizasse novamente no seio da humanidade. Continuando a reflexão do que poderia ter ocasionado o evento de Auschwitz, Adorno (1995) condena a tese de um suposto espírito de confiança germânica. Seria uma tese superficial, pois constata que os países em que aconteceram tais calamidades, como Auschwitz (Polônia), Nazismo (Alemanha) e Fascismo (Itália), como outros países europeus tiveram um passado marcado pelo antigo regime autoritário dos impérios, que deixou profundas marcas na subjetividade dos indivíduos a tal ponto que não souberam lidar com a autodeterminação que os levariam, supostamente, para a liberdade. Há uma jurisdição psicológica humana, por assim dizer, que foge do horizonte da educação, que faz com que o potencial de novamente ocorrer um episódio como Auschwitz seja significativo.

O autor rechaça a concepção de vínculos de compromisso, na qual pessoas com boas intenções apelam para esses vínculos para evitar a ocorrência de uma calamidade como a de Auschwitz. Adorno (1995) considera válido para o âmbito do entendimento humano a imposição de normas que impeçam a manifestação dos elementos irracionais como o sadismo, a loucura. Entretanto não encontra fundamento para essa concepção de vínculos de compromissos, pois uma lei, norma ou mandamento que teria como objetivo barrar o elemento irracional pode culminar com a sua promoção.

O autor aponta que, na Psicologia, o super ego como consciência moral é trocado 
por autoridade exteriores, no caso no universo dos compromissos, resultando em indivíduos altamente dependentes de uma autoridade que não permite qualquer espaço de comunicação ou diálogo, como é o caso da Alemanha depois da queda do Terceiro Reich. Para o autor, é exatamente isso que deve ser extinto: a disponibilidade em ficar ao lado dos poderosos, sob o pretexto do compromisso, entregando a capacidade de crítica, reflexão e a própria liberdade para que outros que não possuem motivações nobres e justas, determinarem o pensamento e a escolha dos comandados. O antídoto eficaz que inibe o princípio ativo de Auschwitz é a autonomia kantiana, como livre exercício de reflexão, conscientização e regulamentação de suas atitudes. Limitando-se aos efeitos e ignorando as causas centrais desse cenário, desenvolvia sua linha de raciocínio a partir de um suposto sentido que poderia existir, na qual todos nós teríamos que extrair lições morais para a vida. Ora, para Adorno (1995) essa verborragia acerca desse episódio não satisfazia eficazmente a problemática, que continuaria a subsistir.

A questão de Adorno (1995) é que quem não encara essa questão de Auschwitz da maneira correta, a de admitir o contato com a questão e refletir agudamente sobre a problemática para fazer emergir as possíveis causas do acontecimento, acaba por corroborar com a possibilidade de acontecer um novo Auschwitz.
Para ele, a educação que tem como alicerce a força excessiva e a disciplina exacerbada é inadequada, pois fez emergir indivíduos sado masoquistas. Essa educação desconsidera as nuances do ser humano como um todo, como por exemplo, a capacidade de sentir dor, e sente a necessidade de transferir os instintos reprimidos ao outro. Quem é severo consigo mesmo adquire o direito de ser severo também com os outros, vingando-se da dor cujas manifestações precisou ocultar e reprimir. A repressão dos instintos forma subjetividades reprimidas que em quaisquer circunstâncias poderão explodir, tal qual um vulcão em erupção. O que Adorno (1995) propõe é que ir até o limite desses sentimentos para que o efeito inconsciente tenha a menor influência possível, já que não é possível estar totalmente alheio ao inconsciente.

\section{Reflexão Sobre Os Indivíduos}

Os indivíduos que se rendem sem o menor grau de reflexão, ou crítica à massificação ostensiva que ocorre na sociedade, transformam-se em materiais e agem pelo princípio da autodeterminação. Adorno (1995) relata que indivíduos com essas características são elegíveis de terem uma personalidade autoritária. Esse caráter autoritário, que equivale a um caráter manipulador, tem como características a fúria organizativa, a dificuldade de lidar com os sentimentos e as emoções e um realismo exacerbado. $\mathrm{O}$ autor relaciona esse 
caráter manipulador com o tipo da consciência coisificada, ou seja, o sujeito humano transmuda-se em objeto inanimado. E quem age como se fosse puramente um objeto, acaba por fazer os outros que estão ao redor também um objeto, como é o caso de jovens que se fortalecem quando estão em um grupo, e os nazistas. O que há em comum entre esses, é a expressão do aprontar como uma forma de desumanidade, tortura, agressão e crueldade sem pestanejar. O que emerge nesse contexto é que esses indivíduos são inaptos a realizar experiências, pois não estão dispostos ao diálogo, ou a qualquer forma de comunicação, e que apresentam doenças mentais e psíquicas.

Ao clarificar o conceito de caráter manipulador, Adorno (1995) lança uma proposta encarnada: se servir do que há de melhor na ciência contemporânea, mais especificamente a Psicanálise para análises profundas e refinadas sobre o contexto macro de Auschwitz, bem como os indivíduos que promoveram tal página negra da humanidade. $\mathrm{E}$ qual seria o papel desses indivíduos frente a não-atualização de Auschwitz? Segundo Adorno (1995) eles devem colaborar com a ciência na investigação, diagnóstico e aplicação de uma solução adequada em resposta a estrutura e comportamento subversivo desse indivíduo.

Para Bauman, há duas razões pelas quais o Holocausto não pode ser reduzido à mera pesquisa bistórica e contemplação filosófica: "A primeira é que, mesmo sendo plausivel que o Holocausto, como acontecimento histórico fundamental - à semelhança da Revolução Francesa, da Descoberta da América on da roda - tenha mudado o curso da bistória subsequente, com toda a certeza mudou pouco, se é que mudou o curso da história subsequente de nossa consciência coletiva e auto percep̧cão. Causou pouco impacto visivel na imagem que fazemos do significado e da tendência histórica da civilização moderna. Deixou as ciências em geral, e a sociologia em particular, virtualmente intactas e imóveis, exceto pelas áreas ainda marginais da pesquisa especializada e por alguns alertas obscuros e sinistros sobre as propensões mórbidas da modernidade. Ambas as exceções mantidas consistentemente à distância do cânone da prática sociológica. Por essas razões, não avançou muito a compreensão dos fatores e mecanismos que um dia tornaram possivel o Holocausto. E com essa compreensão não muito desenvolvida do que se passou meio século atrás poderemos estar mais uma vez. despreparados para notar e decodificar os sinais de alerta - se estiverem agora, como estiveram então, flagrantemente exibidos por toda a parte. A segunda razão é que, o que quer que tenha acontecido ao 'curso da bistória', não aconteceu muita coisa àqueles produtos da história que com toda a probabilidade continham o potencial do Holocausto - ou pelo menos não podemos ter certeza do contrário. Até onde se sabe (ou melhor, até onde não se sabe), eles podem ainda estar entre nós, à espera de uma oportunidade. Só podemos suspeitar que as condições que um dia deram origem ao Holocausto não foram radicalmente transformadas" (BAUMAN, 1998, p. 108-109).

O que não deve ser feito, em nenhuma hipótese, é a repetição de seus métodos e lógica na tentativa de uma melhor compreensão desse indivíduo. Todavia, é possível encontrar uma brecha, um ponto fraco na estrutura do sujeito em questão para que uma mudança seja uma 
possibilidade tangível, e pode ser através do seu orgulho narcisístico. Aprofundando em sua estrutura sádica e perversa, também há a possibilidade de encontrar fragmentos da lei moral que sejam como que oásis no deserto, assim, não seria inatingível uma solução pertinente e adequada que não permita um novo Auschwitz. Entretanto, o que permitira dizer se a solução foi pertinente ou não, é a sua aplicação. Adorno (1995) ainda ressalta que o ser humano não pode ser entendido e explicado de uma maneira mecânica, sem levar suas nuances e o contexto na qual essa consciência foi formada, pois o desvelamento do consciente e do inconsciente estão relacionados a este processo formativo. A consciência reificada não admite abertura a qualquer possibilidade de mudança, e é essencial que haja um aniquilamento desse sistema opressor.

\section{Considerações Finais}

Se as pessoas fossem suficientemente humanas e afetuosas umas com as outras, talvez Auschwitz pudesse não ter ocorrido, como supõe Adorno (1995) . E mesmo se tivessem ocorrido, as pessoas não aceitariam o episódio de uma maneira inerte ou passiva. $\mathrm{O}$ culto exacerbado da subjetividade do indivíduo contemporâneo faz com que ele não leve em consideração nada e ninguém que esteja a sua frente, a não ser seus próprios interesses.

Esta tônica da subjetividade aos extremos tem se entranhado cada vez mais no interior da sociedade contemporânea. É o que acontece com grandes grupos, massa solitária, um emaranhado de pessoas insensíveis que bebem uma das outras o veneno da frieza e da indiferença, sem com que isso mude o cenário reinante. Qualquer um pode queixar-se da ausência do amor, pois antes cada qual não é eficaz na capacidade de externar suas afeições e amor. O culto exagerado da subjetividade gera competição de indivíduos que criam a necessidade ilusória de que o outro é um obstáculo que precisa ser eliminado a qualquer custo. Isso contagia os particulares até tomar conta da coletividade, gerando violência, agressividade e indiferença no tecido social. É por isso que o silêncio e a omissão sobre Auschwitz tomaram dimensões gigantescas.

\section{Referências Bibliográficas e Eletrônicas}

ADORNO, T. W. \& HORKHEIMER, M. Dialética do Esclarecimento. Rio de Janeiro: Jorge Zahar Editor, 1995.

BAUMAN, Zygmunt. Modernidade e holocausto. Rio de Janeiro: Zahar, 1998.

FREUD, S. O mal-estar na civilização. São Paulo: Abril Cultural - Coleção Os Pensadores. 1978.

ADORNO (1995) , T.W. Educação após Auschwitz Disponível em_http:/ /api.ning.com/ files/PS*5K4oSAl4oL3mHrzBpEofK4Ij3FMvc DOm1h*PjaK4w48rBnIwZX27kGnIAHdtSv 
B4imgGdJht2cg9RU1oNqvJExsvRpesv/ausch

witz.pdf . Acesso em 29-05-2009 às 15:10

KANT, Immanuel. O que é esclarecimento?

Disponível em: http://coral.ufsm.br/

gpforma/2senafe/PDF/b47.pdf - Acesso em

29-05-2016 às 18:43

326 fERRARA, R.C.: Algumas Considerações Sobre A Educação Após Auschwitz De Adorno (1995). 